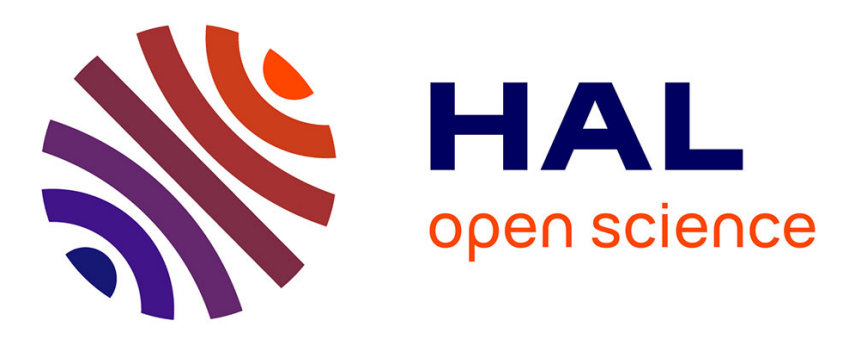

\title{
Molecular tectonics: structural and magnetic properties of a discrete copper binuclear complex and a 1-D coordination network
}

Sylvie Ferlay, Abdelaziz Jouaiti, Marielle Loï, Mir Wais Hosseini, André de Cian, Philippe Turek

\section{To cite this version:}

Sylvie Ferlay, Abdelaziz Jouaiti, Marielle Loï, Mir Wais Hosseini, André de Cian, et al.. Molecular tectonics: structural and magnetic properties of a discrete copper binuclear complex and a 1-D coordination network. New Journal of Chemistry, 2003, 27 (12), pp.1801-1805. 10.1039/B308944B . hal-02301508

\section{HAL Id: hal-02301508 \\ https://hal.science/hal-02301508}

Submitted on 24 Nov 2020

HAL is a multi-disciplinary open access archive for the deposit and dissemination of scientific research documents, whether they are published or not. The documents may come from teaching and research institutions in France or abroad, or from public or private research centers.
L'archive ouverte pluridisciplinaire HAL, est destinée au dépôt et à la diffusion de documents scientifiques de niveau recherche, publiés ou non, émanant des établissements d'enseignement et de recherche français ou étrangers, des laboratoires publics ou privés. 


\title{
Molecular tectonics : structural and magnetic properties of a discrete Copper binuclear complex and a 1-D coordination network
}

\author{
Sylvie Ferlaya, Marielle Loïa, Mir Wais Hosseinia*, André De Ciana, Philippe \\ Turekb \\ a Laboratoire de Tectonique Moléculaire du Solide, Université Louis Pasteur, Institut Le Bel, 4, \\ rue Blaise Pascal, F-67008 Strasbourg Cedex, France \\ Institut Charles Sadron, 6, rue Boussaingault, F-67083 Strasbourg Cedex, France
}

\begin{abstract}
:
Two complexes of general formula $\left[\mathrm{Cu}_{2}\left(\mathrm{pyS}_{4}\right) \mathrm{Cl}_{4}\right] .2 \mathrm{CHCl}_{3}(\mathbf{1})$ and $\left[\mathrm{Cu}_{2}\left(\mathrm{pyS}_{4}\right) \mathrm{Cl}_{2}\right] .2 \mathrm{BF}_{4}$ (2) have been prepared, their crystal structure have been solved, and their magnetic properties have been studied. Complex 1 consists of a binuclear copper (II) units, belonging to the $\mathrm{P} 1$ $2_{1} / \mathrm{n} 1$ space group with $\mathrm{Z}=2, \mathrm{a}=9.7076(3) \AA, \mathrm{b}=12.6420(3) \AA, \mathrm{c}=16.1419(3)$ and $\beta=$ $98.468(2)^{\circ}$. The geometry around each copper atom is closed to a square pyramid. Compound 2 consists of a chain of $\mu$-halogeno binuclear copper(II) units, belonging to the $C 12 / \mathrm{c} 1$ space group with $Z=4, a=32.475(3) \AA, b=13.496(2) \AA, c=8.7380(5)$ and $\beta=96.335(6)$. The geometry around each copper atom is closed to a square pyramid and the chains are packed in the manner that tubular features are formed, where the $\mathrm{BF}_{4}{ }_{4}^{-}$anions lye. Compound $\mathbf{2}$ behaves magnetically like a chloro-bridged copper (II) dimer, and a ferromagnetic coupling is observed between the two spin bearers $(\mathrm{d}=3.467 \AA)\left(\mathrm{J} / k_{\mathrm{B}}=337 \mathrm{~K}\right)$, and a dimer-dimer antiferromagnetic interaction $\left(z \mathrm{~J}^{\prime} / k_{\mathrm{B}}=-1.6 \mathrm{~K}\right)$. The $\mathrm{Cu}-\mathrm{Cl}-\mathrm{Cu}$ angle of $85.5^{\circ}$ is consistent with a ferromagnetic interaction between the copper (II) atoms.
\end{abstract}

Key words : Pyridine, Thioether, $\mathrm{Cu}$ (II), Structure, Coordination network, Binuclear, Magnetism

Prof. M. W. Hosseini, Université Louis Pasteur, Institut Le Bel, 4, rue Blaise Pascal 67000 Strasbourg, France, Tel. : 33390 241323, Fax : 33390241325

e-mail : hosseini@chimie.u-strasbg.fr 


\section{Introduction}

The design of molecular architectures in the solid state is a subject of current investigation. In particular, the formation of coordination networks ${ }^{1}$, hybrid metallo-organic molecular assemblies is attracting much attention over the last decade. These networks may be defined as infinite structures resulting from interactive self-assembling processes based on the formation of coordination bonds between organic and metallic tectons or active building blocs. In terms of structural control, the gathered knowledge over the last years allows today to design, with an acceptable degree of confidence (predesign and reproducibility), coordination networks or polymers with defined connectivity and thus dimensionality. The generation in the solid-state of coordination networks under self-assembly conditions results on one hand from the binding events taking place between the coordinating sites located on the organic tecton and the available coordination sites on the metal centre thus defining the assembling cores, and on the other hand, the iteration of the binding process allowing the translation of the assembling cores which become nodes of the network. The dimensionality of the network, i.e. 1-, 2- or 3$\mathrm{D}$, is defined by the number of translations of the assembling cores into one, two or three directions of space respectively. Dealing with 1- and 2-D networks, the generation of the solid material, obviously, depends on the packing of the networks.

The majority of coordination networks reported are based on the use of cationic metal centres. For charge neutrality reasons, this implies that either the presence of an anionic organic tecton or the presence of anions in the case of neutral organic tectons. For the latter case, we have previously shown that, as a design principle, one may take advantage of the presence of the anion to direct the self-assembly processes. ${ }^{2}$

A further step which remains to be achieved consists in the incorporation of physical properties within the molecular tectons in order to obtain functional networks. These properties may be in the areas of optics, molecular electronics or magnetism. For the latter case, a variety of materials with various dimensionality ranging from isolated species to 1-D chains, 2-D sheets or three-dimensional compounds displaying specific magnetic properties have been produced. ${ }^{3}$

Pursuing our efforts to design coordination networks in the crystalline phase, ${ }^{4}$ here we present the obtention of a discrete binuclear cooper (II) complex, its extension to a 1-D network through the use of a mixed anion cooper salt and their magnetic properties.

The organic tecton 1 (scheme 1), a symmetrical bis-tridentate ligand based on two pyridines and four thioether units of $\mathrm{Py}_{2} \mathrm{~S}_{4}$ type was chosen because of its ability to generate 1and 2-D networks with transition metals, in particular with $\mathrm{Cd}$ (II). ${ }^{5}$

\section{Scheme}


We have previously demonstrated that in the case of cadmium (II), depending on the binding ability of the anion, a 1-D or a 2-D coordination network may be generated. Indeed, whereas in the presence of chloride anion a 1-D network is formed, the use of a mixed anion cadmium salt $\left(\mathrm{CdClBF}_{4}\right)$, a 2-D network is generated. ${ }^{5}$ For both cases, the metal centre adopts an octahedral coordination geometry and the networks are obtained through bridging of metallic centres by chloride anions.

Based on the above mentioned observation, demonstrating the important role played by the anion in the formation and dimensionality of coordination network, the approach was further extended to the design of a functional network based on copper (II) as magnetically active centre. The rational approach was supported by the rather short distance (3.94 $⿱$ ) observed between chloro bridged diamagnetic cadmium cations which, in the case of $\mathrm{Cu}$ (II) could lead to reasonable magnetic interactions between paramagnetic centres.

Many extended coordination networks based on the bridging by halogen atoms and organic ligands of transition metal ions have been reported in the literature ${ }^{6}$. Copper (II) based networks containing $\mathrm{N}$ donor atoms have been extensively studied with respect to the intramolecular magnetic exchange between the metal centres through multiatomic bridges (halogens, organic ligand) as well as intermolecular interactions ${ }^{7}$. As an example, an antiferromagnetic coupling around $-200 \mathrm{~cm}^{-1}$ is reported for a chain containing a 2,2'bipyrimidine ligand and octahedral copper (II) atoms, with a $\mathrm{Cu}-\mathrm{Cu}$ shortest distance of 3.60 $\AA^{6 b}$. For dimeric species, depending on the $\mathrm{Cu}-\mathrm{Cl}-\mathrm{Cu}$ angle, for the majority of studied cases, antiferromagnetic interactions have been observed. ${ }^{8}$ However, few examples of ferromagnetic coupling for dimeric species have been also reported. In particular, recently, a ferromagnetic coupling with a $\mathrm{J}$ value around $+50 \mathrm{~cm}^{-1}$ has been reported for a distorted square pyramidal binuclear copper complex. ${ }^{9}$

\section{Results and discussion}

\section{Structural Analysis}

Both solid materials $\mathbf{2}$ and $\mathbf{3}$ were obtained as single crystals, under self assembly conditions, upon slow liquid-liquid diffusion (see Table 1 for X-ray data). Both compounds have been also synthesised as polycrystalline samples and characterised by elemental synthesis which revealed the presence of water molecules in the case of $\mathbf{3}$.

The discrete neutral binuclear complex 2 was formed in a mixture of solvents using a 1/1 ratio of 1 and $\mathrm{CuCl}_{2}$ (see experimental section for details). The structural study on single crystal revealed the following features (figure 1): the crystal is composed of discrete binuclear complexes 2 and $\mathrm{CHCl}_{3}$ solvent molecules. The binuclear complex presents a centre of symmetry. For the organic ligand, both pyridine rings are tilted by $c a 47^{\circ}$ with respect to the phenyl group. The CS and CN distances of $1.797 \AA$ and of $1.345 \AA$ and NCCS dihedral angles of $-4.2^{\circ}$ and $-25.7^{\circ}$ are roughly the same as those observed for the free ligand $1 .^{5}$ For 
both $\mathrm{Cu}$ (II) atoms, the coordination sphere around the metal is composed of one $\mathrm{N}$ atom $\left(\mathrm{d}_{\mathrm{N}}\right.$ $\mathrm{Cu}=2.015 \AA$ ), two $\mathrm{S}$ atoms ( $\mathrm{d}_{\mathrm{S}-\mathrm{Cu}}=2.349 \AA$ and $\left.2.355 \AA\right)$ and two terminal $\mathrm{Cl}^{-}$anions with one short and one long $\mathrm{Cu}-\mathrm{Cl}$ distances $\left(\mathrm{d}_{\mathrm{Cl}-\mathrm{Cu}}=2.248 \AA\right.$ and $\left.2.462 \AA\right)$. The coordination geometry for both metal centres is a distorted square pyramid (SCuN angles of $84.7^{\circ}$ and $83.9^{\circ}, \mathrm{NCuCl}$ angles of $95.3^{\circ}$ and $162.6^{\circ}, \mathrm{SCuS}$ angle of $157.5^{\circ}$ and $\mathrm{ClCuCl}$ angle of $102.0^{\circ}$ ). The $\mathrm{Cu}-\mathrm{Cu}$ distance is $15.343 \AA$. $\mathrm{CHCl}_{3}$ solvent molecules are located between the dimeric units 2 with no specific interactions with them.

\section{Figure 1}

The one-dimensional network 3 was generated in a mixture of solvents using an equimolar ratio of tecton 1 and a mixed $\mathrm{Cl}^{-}$and $\mathrm{BF}_{4}^{-}$copper (II) salt $\left(\mathrm{CuClBF}_{4}\right.$ ) (see experimental section). The structural study on single crystal revealed the following features (figure 2) : the crystal is exclusively composed of $\mathbf{1}, \mathrm{Cu}$ (II) atoms, $\mathrm{Cl}^{-}$and $\mathrm{BF}_{4}^{-}$anions. No solvent molecule is present in the solid. Tecton $1, \mathrm{Cu}$ (II) dication and $\mathrm{Cl}^{-}$anion form a cationic 1-D coordination networks. The 1-D network 3 results from the translation into one space direction of the assembling cationic core defined by $\left[\mathrm{pyS}_{4} \mathrm{Cu}_{2} \mathrm{Cl}_{2}\right]^{2+}$ unit. In other terms, the network is generated through bridging of binuclear complexes 2 by both chloride centres. The charge neutrality is then achieved by $\mathrm{BF}_{4}^{-}$anions occupying the empty space in the lattice.

For the ligand part, the pyridine rings are again tilted by about $30^{\circ}$ and $33^{\circ}$ with respect to the phenyl group. The CS and CN distances of $1.812 \AA$ and of $1.352 \AA$ are roughly the same as those observed for the free ligand $\mathbf{1}^{5}$ and for the discrete binuclear complex $\mathbf{2}$ mentioned above. The NCCS dihedral angles are $23.5^{\circ}$ and $21.2^{\circ}$.

Copper(II) cation is again surrounded by five donor atoms with its coordination sphere composed of one $\mathrm{N}$ atom $\left(\mathrm{d}_{\mathrm{N}-\mathrm{Cu}}=1.971 \AA\right)$, two $\mathrm{S}$ atoms $\left(\mathrm{d}_{\mathrm{S}-\mathrm{Cu}}=2.314 \AA\right.$ and $2.325 \AA$ ) and two bridging $\mathrm{Cl}^{-}$anions with again one short and one long $\mathrm{Cu}-\mathrm{Cl}$ distances $\left(\mathrm{d}_{\mathrm{Cu}-\mathrm{Cl}}=2.239 \AA\right.$ and $2.828 \AA$ ). The coordination geometry around the $\mathrm{Cu}(\mathrm{II})$ centre is again a distorted square pyramid ( $\mathrm{SCuN}$ angles of $86.4^{\circ}$ and $85.6^{\circ}, \mathrm{NCuCl}$ angles of $89.2^{\circ}$ and $176.3^{\circ}, \mathrm{SCuS}$ angle of $171.9^{\circ}$ and $\mathrm{ClCuCl}$ angle of $94.5^{\circ}$ ). The distance between two $\mathrm{Cu}$ atoms located at each extremity of the tecton $\mathbf{1}$ of $15.323 \AA$ is close to the one mentioned above for the discrete binuclear complex 2 (15.343 $\AA$ ). The $\mathrm{Cu}-\mathrm{Cu}$ distance between halide bridged centres is 3.467 $\AA$. This distance is shorter than the one observed for $\left[\mathrm{Cu}_{2}(\mathrm{dpt})_{2} \mathrm{Cl}_{2}\right] \mathrm{Cl}_{2}$ dimeric analogue

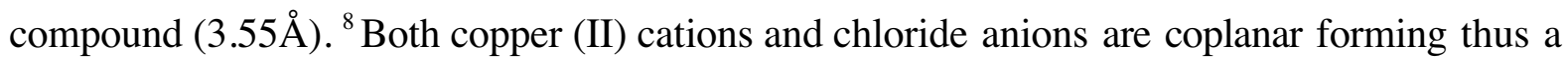
rectangle with $\mathrm{CuClCu}$ angle of $85.5^{\circ}$.

\section{Figure 2}

Within a layer, perpendicular to the c axis, the 1-D networks are packed in a parallel fashion. For consecutive layers, the 1-D networks are tilted by $30^{\circ}$ (Figure 3 ). This arrangement of 
layers leads to the formation of large channels with a diameter of $c a 10.8 \AA$ in the crystal which are occupied by $\mathrm{BF}_{4}{ }^{-}$anions. The analysis of the packing of 1-D networks reveals the shortest interchain distance of $c a 4.2 \AA$ between superimposed phenyl rings of the tecton 1 . The shortest interchain $\mathrm{Cu}-\mathrm{Cu}$ distance is $7.6 \AA$.

\section{Figure 3}

The main difference between the discrete binuclear complex 2 and the 1-D coordination network 3 generated in the presence of $\mathbf{1}$ and the 1- and 2-D networks obtained with $\mathrm{Cd}$ (II) ${ }^{5}$ is due to the coordination geometry around the metallic centre. Indeed, whereas in the case of $\mathrm{Cd}$ (II), the metal centre adopts an octahedral coordination geometry thus allowing the formation of 1- and 2-D networks depending on the number of bridging chloride anions, in the case of $\mathrm{Cu}$ (II) adopting a square pyramidal geometry, one would expect either the discrete binuclear complex $\mathbf{2}$ in the absence of bridging or the infinite 1-D network 3 for the bridging situation.

\section{Magnetic properties}

The $\chi_{\mathrm{M}} \mathrm{T}$ values at room temperature are equal to 0.78 and $0.83 \mathrm{~cm}^{3} \mathrm{Kmol}^{-1}$ for the discrete binuclear complex 2 and the infinite network 3 respectively. These values are in accordance with two non interacting $1 / 2$ spins centred on $\mathrm{Cu}$ (II) cations.

For the complex 2 , the two paramagnetic $\mathrm{Cu}$ (II) centres behave as two almost isolated spins. However, below $25 \mathrm{~K}$, a decrease of the $\chi \mathrm{T}$ product is observed indicating a weak antiferromagnetic interaction.

For infinite network 3 , the $\chi_{\mathrm{M}}^{\mathrm{T}} v s$. T curve is shown on figure 4 . The $\chi_{\mathrm{M}}^{\mathrm{T}}$ value increases continuously when the temperature decreases, with a maximum value of $0.92 \mathrm{~cm}^{3} \mathrm{Kmol}^{-1}$ at $c a$. $80 \mathrm{~K}$. This is in agreement with a ferromagnetic interaction between both copper (II) spin bearers. Below this maximum, $\chi_{\mathrm{M}} \mathrm{T}$ value decreases with the temperature, which is consistent with a weak interchain antiferromagnetic interaction. Since the origin of such possibly efficient magnetic interchain contacts is not well addressed, the overall behaviour was simulated upon introducing a mean field correction to the dimer equation representing the singlet-triplet (ST) equilibrium:

$$
\chi^{\top}=\frac{\chi_{S T}^{\top}}{1-\frac{\mathrm{ZJ}^{\prime \prime}}{\mathrm{k}_{\mathrm{B}}} \chi_{\mathrm{ST}}}
$$

with $\chi_{S T}=\frac{C}{T 3+\exp \left(-J K_{B} T\right)}$ where $C=\frac{2 \mathrm{Ng}^{L} \beta^{L}}{3 K_{B}}$

A rather good fit is obtained $(\mathrm{R}=0.997)$ with a triplet ground state and a ST gap $J / \mathrm{k}_{\mathrm{B}}=337^{ \pm} 10$ $\mathrm{K}$, and an antiferromagnetic mean field correction $z J^{\prime} / \mathrm{k}_{\mathrm{B}}=-1.6^{ \pm} 0.1 \mathrm{~K}$ and $\mathrm{g}=2.04$. 


\section{Figure 4}

Magnetization vs. field experiments, performed at $4 \mathrm{~K}$ up to a field at $60000 \mathrm{G}$ for compounds $\mathbf{2}$ and $\mathbf{3}$, exhibit a Brillouin function behaviour close to the one expected for a $S=1$ ground state. For both $\mathbf{2}$ and $\mathbf{3}$ systems, no hysteresis was observed.

The EPR spectra of a polycrystalline sample of $\mathbf{2}$ or $\mathbf{2}$ recorded at room temperature are assigned to isolated $\mathrm{Cu}$ (II) species with an axial $\boldsymbol{g}$ tensor $\left(g_{\perp}=2.060 ; g_{/ /}=2.015 ; g_{a v}=2.045\right.$ for both compounds $)$. It is worth noting that the measured value of the average g-factor is close to the value given for the fit of the magnetic susceptibility data.

The investigation pointed out a relatively strong ferromagnetic interaction between two $\mu$ chloro bridged copper (II) atoms in the 1-D network 3 . The high value of $337 \mathrm{~K}$ given by the fit is substantially higher than the $50 \mathrm{~cm}^{-1}$ found for the analogous $\left.\mathrm{Cu}_{2}(\mathrm{dpt})_{2} \mathrm{Cl}_{2}\right] \mathrm{Cl}_{2}$ complex, for which the copper (II) atoms adopt the same square pyramidal geometry. ${ }^{9}$ This may be explained by the short distance between the copper(II) atoms observed in the case of the infinite network $3(3.46 \AA)$ instead of $3.55 \AA$ for the $\left[\mathrm{Cu}_{2}(\mathrm{dpt})_{2} \mathrm{Cl}_{2}\right] \mathrm{Cl}_{2}$ complex, as well as a different $\mathrm{CuClCu}$ angle $\left(85.5^{\circ}\right.$ in the case of 3 and $90.1^{\circ}$ for the $\left[\mathrm{Cu}_{2}(\mathrm{dpt})_{2} \mathrm{Cl}_{2}\right] \mathrm{Cl}_{2}$ complex).

However, no real one-dimensional magnetic behaviour is observed for the network $\mathbf{3}$, although a weak interdimer antiferromagnetic interaction resulting probably from the interchain distance of $c a 7 \AA$ could be detected.

\section{Conclusion}

In conclusion, using the tecton 1 , a symmetrical bis-tridentate unit of the $\mathrm{Py}_{2} \mathrm{~S}_{4}$ type and $\mathrm{Cu}$ (II) cation, the binuclear discrete complex 2 as well as the infinite 1-D coordination network 3 have been obtained and structurally characterised in the solid state by X-ray diffraction method on single crystal. Whereas for the discrete complex 2 , the two paramagnetic $\mathrm{Cu}$ (II) cations behaved as almost independent centres, for the infinite network $\mathbf{3}$, the magnetic study revealed a strong ferromagnetic interactions between the copper (II) centres, probably the highest observed for square pyramidal $\mu$-chloro bridged copper system. However, no cooperative phenomenon was observed between the dimers.

\section{Experimental Section}

The synthesis of the ligand $\mathbf{1}$ was previously described. The synthesis of the mixed $\mathrm{Cl}^{-}$and $\mathrm{BF}_{4}^{-}$Copper (II) salt, $\left(\mathrm{CuClBF}_{4} \times \mathrm{H}_{2} \mathrm{O}\right)$, was achieved by mixing an equimolar ratio of $\mathrm{CuCl}_{4}$ $\cdot 2 \mathrm{H}_{2} \mathrm{O}$ and $\mathrm{NaBF}_{4}$.

Synthesis of the discrete binuclear complex 2 : Slow diffusion at room temperature of a $\mathrm{MeOH}$ solution containing $\mathrm{CuCl}_{2} \cdot 2 \mathrm{H}_{2} \mathrm{O}\left(6.10^{-6}\right.$ moles $)$ into a $\mathrm{CHCl}_{3}$ solution of the ligand 1 
(6. $10^{-6}$ moles) afforded green crystals after $24 \mathrm{~h}$. The microcrystalline material could also be obtained at room temperature upon mixing a $\mathrm{MeOH}$ solution of $\mathrm{CuCl}_{2} \cdot 2 \mathrm{H}_{2} \mathrm{O}\left(6.10^{-3}\right.$ moles $)$ with a $\mathrm{CHCl}_{3}$ solution of the ligand $1\left(6.10^{-3}\right.$ moles $)$. The green precipitate was then filtered and dried under vacuum. Molecular formula : $\mathrm{C}_{24} \mathrm{H}_{28} \mathrm{Cl}_{4} \mathrm{Cu}_{2} \mathrm{~N}_{2} \mathrm{~S}_{4} \cdot 2 \mathrm{CHCl}_{3}\left(980.41 \mathrm{gmol}^{-1}\right)$. Elemental analysis: calcd : C: $31.9 \%, \mathrm{H}: 3.1 \%, \mathrm{~N}: 2.9 \%$; found : C: $31.0 \%, \mathrm{H}: 3.1 \%, \mathrm{~N}$ : $2.9 \%$.

Generation of the 1-D network 3 : Slow diffusion at room temperature of a $\mathrm{EtOH}$ solution containing $\mathrm{CuClBF}_{4} \times \mathrm{H}_{2} \mathrm{O}\left(6.10^{-6}\right.$ moles $)$ into a $\mathrm{CHCl}_{3}$ solution of the ligand 1 (6. $10^{-6}$ moles) afforded blue-green crystals. The microcrystalline material could also be obtained by mixing an EtOH solution of $\mathrm{CuClBF}_{4} \cdot \mathrm{x} \mathrm{H}_{2} \mathrm{O}\left(6.10^{-3}\right.$ moles) with a $\mathrm{CHCl}_{3}$ solution of 1 (6. $10^{-3}$ moles). The blue-green precipitate was then filtered and dried under vacuum. Molecular formula for the crystals: $\mathrm{C}_{24} \mathrm{H}_{28} \mathrm{Cl}_{2} \mathrm{Cu}_{2} \mathrm{~N}_{2} \mathrm{~S}_{4} \cdot 2 \mathrm{BF}_{4}\left(844.36\right.$ gmol $\left.{ }^{-1}\right)$. Elemental analysis: calcd (with 5 supplementary $\mathrm{H}_{2} \mathrm{O}$ molecules): $\mathrm{C}: 30.9 \%, \mathrm{H}: 4.1 \%, \mathrm{~N}: 3.0 \%$; found : $\mathrm{C}: 31.6 \%, \mathrm{H}$ : $3.2 \%, \mathrm{~N}: 2.9 \%$.

\section{Characterization and physical measurements}

The EPR spectra of polycrystalline powders were recorded at $100 \mathrm{~K}$ and at room temperature using an ESP 300 E spectrometer (BRUKER). A TE102 rectangular cavity was used, and all spectrometers parameters were adjusted so as to get the best $\mathrm{S} / \mathrm{N}$ ratio without distorting the signal.

Magnetic susceptibility data of the powdered samples were collected with a MPMS Quantum Design SQUID magnetometer in the temperature range of $300-1.8 \mathrm{~K}$ at a field of $1000 \mathrm{G}$. The sample holder was a quartz tube. The output data were corrected for the experimentally determined diamagnetism of the sample holder and the diamagnetism of the samples calculated from Pascal's constants.

Crystal structure characterization : X-ray diffraction data collection was carried out on a Kappa CCD diffractometer equipped with an Oxford Cryosystem liquid $\mathrm{N}_{2}$ device, using graphite-monochromated Mo-K $\alpha$ radiation. For all structures, diffraction data were corrected for absorption and analysed using OpenMolen package. ${ }^{10}$ All non-H atoms were refined anisotropically. CCDC 215577 and 215578 contains the supplementary crystallographic data for compounds 2 and 3 respectively. These data can be obtained free of charge at www.ccdc.cam.ac.uk/conts/retrieving.html or from the Cambridge Crystallographic data Center, 12 Union Road, Cambridge CB2 1EZ, UK; Fax: (Internat.) +44-1223/336-033; Email: deposit@ccdc.cam.ac.uk.

X-ray data for the discrete binuclear complex $\mathbf{2}$ and the infinite network $\mathbf{3}$ are summarized in Table 1. 


\section{Acknowledgement}

We thank the Universite Louis Pasteur and the Ministry of Research and Education for

financial support. We thank Pr. S. Decurtins (Universität Bern, Switzerland) for having performed the SQUID measurements. 


\section{References}

[1] a) R. Robson, Comprehensive Supramolecular Chemistry, J-L. Atwood, J.E.D. Davies, D.D. Macnicol, F. Vögtle Eds., vol 6, 1996, p 733.

b) O.M. Yaghi, H. Li, C. Davis, D. Richardson, T.L. Groy, Acc. Chem. Res., 1998, 31, 474.

[2] a) A. Jouaiti, M. W. Hosseini, A. De Cian, Chem. Comm., 2000, 1863.

b) A. Jouaiti, M. W. Hosseini, N. Kyritsakas, Chem. Comm, 2002, 1898.

c) P. Grosshans, A. Jouaiti, M. W. Hosseini, N. Kyritsakas, New J. Chemistry, 2003, 27, 793.

[3] a) O. Kahn, Molecular Magnetism, VCH, Weinheim, Germany, 1993.

b) O. Kahn Ed., Molecular Magnetism, a Supramolecular Fuction, Kluwer, Dordrecht, The Netherlands, 1996.

[4] a) C. Kaes, M. W. Hosseini, C. E. F. Rickard, B. W. Skelton, A. White, Angew. Chem. Int. Ed. Engl., 1998, 37, 920 .

b) G. Mislin, E. Graf, M. W. Hosseini, A. De Cian, N. Kyritsakas, J. Fischer, Chem. Comm., 1998, 2545.

c) M. Loï, M. W. Hosseini, A. Jouaiti, A. De Cian, J. Fischer, Eur. J. Inorg. Chem., 1999, 1981.

d) C. Klein, E. Graf, M. W. Hosseini, A. De Cian, J. Fischer, Chem. Comm., 2000, 239.

e) B. Schmaltz, A. Jouaiti, M. W. Hosseini, A. De Cian, Chem. Comm., 2001, 1242.

f) A. Jouaiti, V. Jullien, M. W. Hosseini J.-M. Planeix, A. De Cian, Chem. Comm., 2001, 1114.

g) C. Klein, E. Graf, M. W. Hosseini, A. De Cian, J. Fischer, New J. Chem, 2001, 25, 207.

h) S. Ferlay, S. Koenig, M. W. Hosseini, J. Pansanel, A. De Cian, N. Kyritsakas, Chem. Comm, 2002, 218

i) B. Zimmer, M. Hutin, V. Bulach, M. W. Hosseini, A. De Cian, N. Kyritsakas, New. J. Chem, 2002, 26,1532

j) A. Jouaiti, M. W. Hosseini, N. Kyritsakas, Eur. J. Inorg. Chem. 2002, 57.

k) B. Zimmer, V. Bulach, M. W. Hosseini, A. De Cian, N. Kyritsakas, Eur. J. Inorg. Chem, $2002,3079$.

1) A. Jouaiti, M. W. Hosseini, N. Kyritsakas, Chem. Comm, 2003, 472.

[5] M. Loï, E. Graf, M.W. Hosseini, A. De Cian, J. Fischer, Chem. Comm., 1999, 603.

[6] a) M. Megnamisi-Belombe, P. Singh, D.E. Bolster, W.E. Hatfield, Inorg. Chem., 1984, 23, 2578.

b) M. Julve, G. De Munno, G. Bruno, M. Verdaguer, Inorg. Chem., 1988, 27, 3160.

c) R.E. Marsh Inorg. Chem., 1990, 29, 572.

c) O.M. Yaghi, Guangming Li, Angew. Chem. Int. Ed. Engl., 1995, 34, 207.

e) A. Neels, B.M. Neels, H. Stoeckli-Evans, A. Clearfield, D.M. Poojary Inorg. Chem., 1997, $36,3402$.

[7] a) M. Julve, M. Verdaguer, O. Kahn, A. Gleizes, M. Philoche-Levisalles, Inorg. Chem., 1984, $23,3808$.

b) R. Vicente, J. Ribas, S. Alvarez, X. Solans, M. Fontaltaba M. Verdaguer, Inorg. Chem., 1987, 26, 4004.

[8] (a) S.G.N. Roundhill, D.M.Roundhill, D.R Bloomquist, C. Landee, R.D. Willett, D.M. Dooley, H.B. Gray, Inorg. Chem. 1979, 18, 831.

(b) D.J. Hodgson, E. Pedersen, Acta Chem. Scand. A 1982, 36, 281.

(c) A. Tosik, W. Maniukievicz, M. Bukowska-Strzyzewska, J. Mrozinski, M.P. Sigalas, C.A. Tsipis, 
Inorg. Chim. Acta 1991, 190, 193.

(d) M. Graf, B. Greaves, H. Stoeckli-Evans, Inorg. Chim. Acta 1993, 204, 239.

[9] M. Rodriguez, A. LLobet, M. Corbella, A. Martell, J. Reibenspies, Inorg. Chem., 1999, 38, 2329.

[10] OpenMolenN, Interactive Structure Solution, Nonius B. V., Delft, The Netherlands, 1997. 
Table 1 : Data collection and refinements for $\mathbf{2}$ and $\mathbf{3}$.

\begin{tabular}{|c|c|c|}
\hline & 2 & 3 \\
\hline Empirical Formula & $\begin{array}{c}\mathrm{C}_{24} \mathrm{H}_{28} \mathrm{Cl}_{4} \mathrm{Cu}_{2} \mathrm{~N}_{2} \mathrm{~S}_{4} \cdot 2 \\
\mathrm{CHCl}_{3} \\
980.41\end{array}$ & $\begin{array}{c}\mathrm{C}_{24} \mathrm{H}_{28} \mathrm{Cl}_{2} \mathrm{Cu}_{2} \mathrm{~N}_{2} \mathrm{~S}_{4} \cdot 2 \mathrm{~B} \\
\mathrm{~F}_{4} \\
844.36\end{array}$ \\
\hline Crystal system & Monoclinic & Monoclinic \\
\hline Space group & P $121 / n 1$ & C $12 / \mathrm{c} 1$ \\
\hline 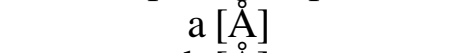 & $9.7076(3)$ & $32.475(3)$ \\
\hline $\mathrm{b}[\AA]$ & $12.6420(3)$ & $13.496(2)$ \\
\hline$c[\AA]$ & $16.1419(3)$ & $8.7380(5)$ \\
\hline$\alpha\left[^{\circ}\right]$ & & \\
\hline$\beta\left[^{\circ}\right]$ & $98.468(2)$ & $96.335(6)$ \\
\hline$\gamma\left[^{\circ}\right]$ & & \\
\hline $\mathrm{V}\left[\AA^{3}\right]$ & $1959.4(2)$ & $3806(1)$ \\
\hline $\begin{array}{l}\mathrm{Z} \\
\text { color }\end{array}$ & $\begin{array}{c}2 \\
\text { blue }\end{array}$ & $\begin{array}{c}4 \\
\text { blue }\end{array}$ \\
\hline Crystal size [mm] & $0.20 * 0.15 * 0.10$ & $0.20 * 0.12 * 0.04$ \\
\hline$\rho_{\text {calcd }}\left[\mathrm{g} \mathrm{cm}^{-3}\right]$ & 1.66 & 1.47 \\
\hline $\mathrm{F}(000)$ & 984 & 1696 \\
\hline$\mu\left[\mathrm{mm}^{-1}\right]$ & 2.003 & 1.534 \\
\hline Temperature $[\mathrm{K}]$ & 173 & 294 \\
\hline$\lambda[\AA]$ & 0.71073 & 0.71073 \\
\hline Radiation & $\begin{array}{l}\text { MoK }_{\alpha} \text { graphite } \\
\text { monochromated }\end{array}$ & $\begin{array}{l}\text { MoK }_{\alpha} \text { graphite } \\
\text { monochromated }\end{array}$ \\
\hline Diffractometer & KappaCCD & KappaCCD \\
\hline Scan mode & phi scans & phi scans \\
\hline $\mathrm{h} / \mathrm{k} / \mathrm{l}$ ranges & $0,11 / 0,15 /-18,17$ & $0,42 /-17,17 /-11,11$ \\
\hline$\theta$ range for collection $\left[{ }^{\circ}\right]$ & $2.5 / 28.06$ & $2.5 / 27.54$ \\
\hline $\begin{array}{l}\text { Number of reflections } \\
\text { collected }\end{array}$ & 13947 & 9265 \\
\hline $\begin{array}{l}\text { Number of data with } \mathrm{I}>3 \\
\mathrm{~s}(\mathrm{I})\end{array}$ & 3042 & 2330 \\
\hline Weighting scheme & $\begin{array}{c}4 \mathrm{Fo}^{2} / \mathrm{s}^{2}\left(\mathrm{Fo}^{2}\right)+ \\
\left.0.0064 \mathrm{Fo}^{4}\right)\end{array}$ & $\begin{array}{c}4 \mathrm{Fo}^{2} /\left(\mathrm{s}^{2}\left(\mathrm{Fo}^{2}\right)+0.000\right. \\
\left.9 \mathrm{Fo}^{4}\right)+1.0\end{array}$ \\
\hline Number of variables & 199 & 199 \\
\hline $\mathrm{R}$ & 0.033 & 0.057 \\
\hline Rw & 0.063 & 0.102 \\
\hline GOF & 1.327 & 1.616 \\
\hline $\begin{array}{l}\text { Largest peak in final } \\
\text { difference }\left(e \AA^{-3}\right)\end{array}$ & 0.607 & 0.432 \\
\hline
\end{tabular}




\section{Figure caption}

Figure 1 : $\mathrm{X}$ ray structure of the discrete binuclear copper complex 2 formed upon mixing the ligand 1 with $\mathrm{CuCl}_{2}$. Solvent molecules and $\mathrm{H}$ atoms are not represented for sake of clarity. For bond distances and angles see text.

Figure 2 : A portion of the $X$ ray structure of the infinite 1-D coordination network 3 obtained upon self-assembly between the tecton 1 and $\mathrm{CuClBF}_{4}$ mixed salt. Only one 1$\mathrm{D}$ network is represented. $\mathrm{BF}_{4}^{-}$anions and $\mathrm{H}$ atoms are not represented for sake of clarity. For bond distances and angles see text.

Figure 3 : A portion of the $X$ ray structure of 3 showing the packing of consecutive 1-D networks leading to the formation of channels. $\mathrm{BF}_{4}^{-}$anions and $\mathrm{H}$ atoms are not represented for sake of clarity.

Figure $4: \chi_{\mathrm{M}} \mathrm{T} v s$. $\mathrm{T}$ experimental data for the infinite 1-D coordination network 3 . The best fit is represented by the solid line. 

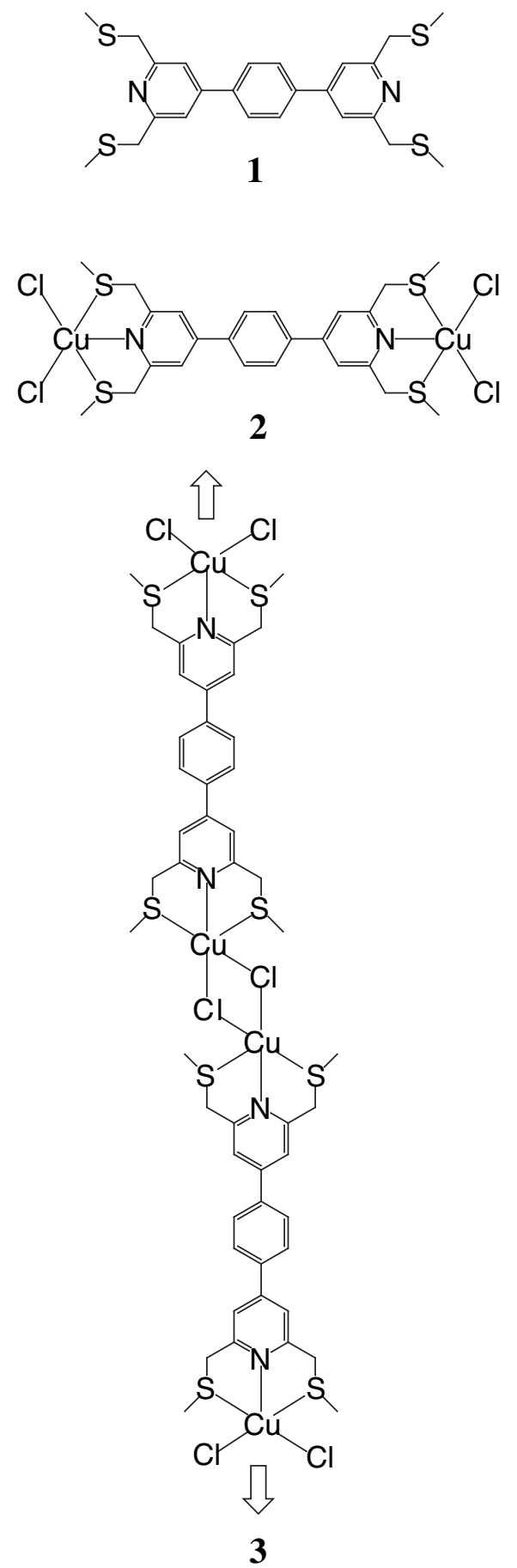

Scheme 


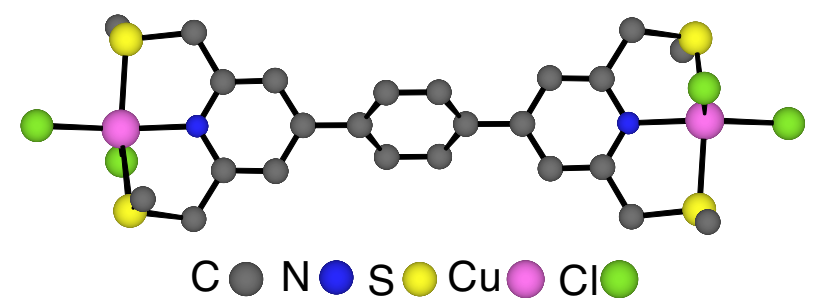

Figure 1

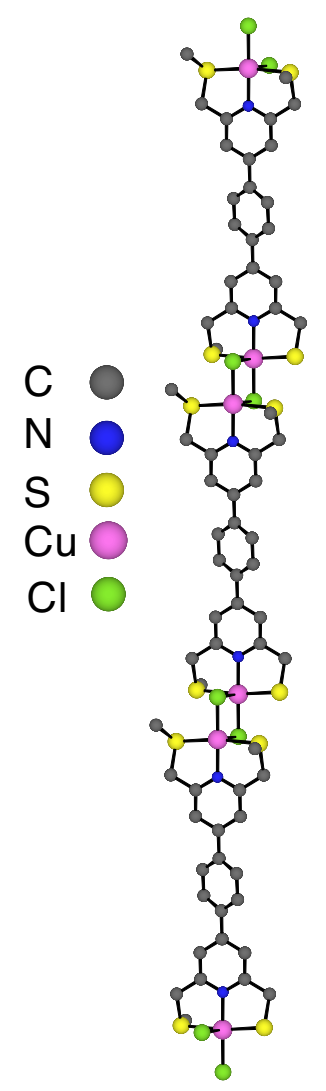

Figure 2

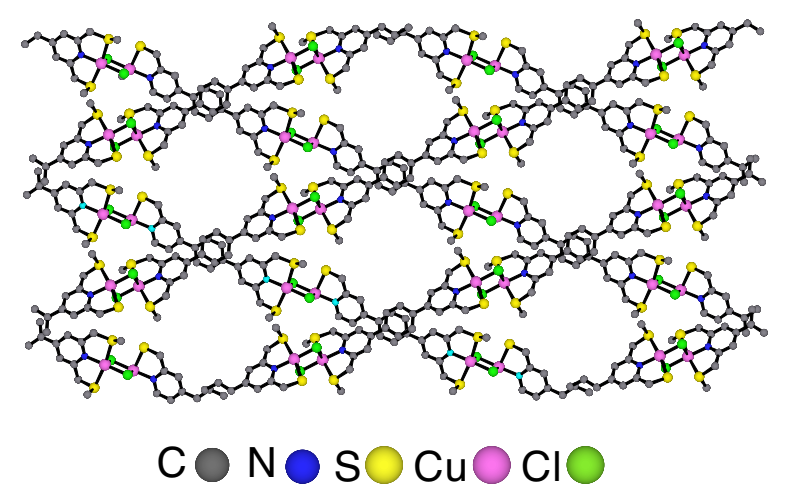

Figure 3 


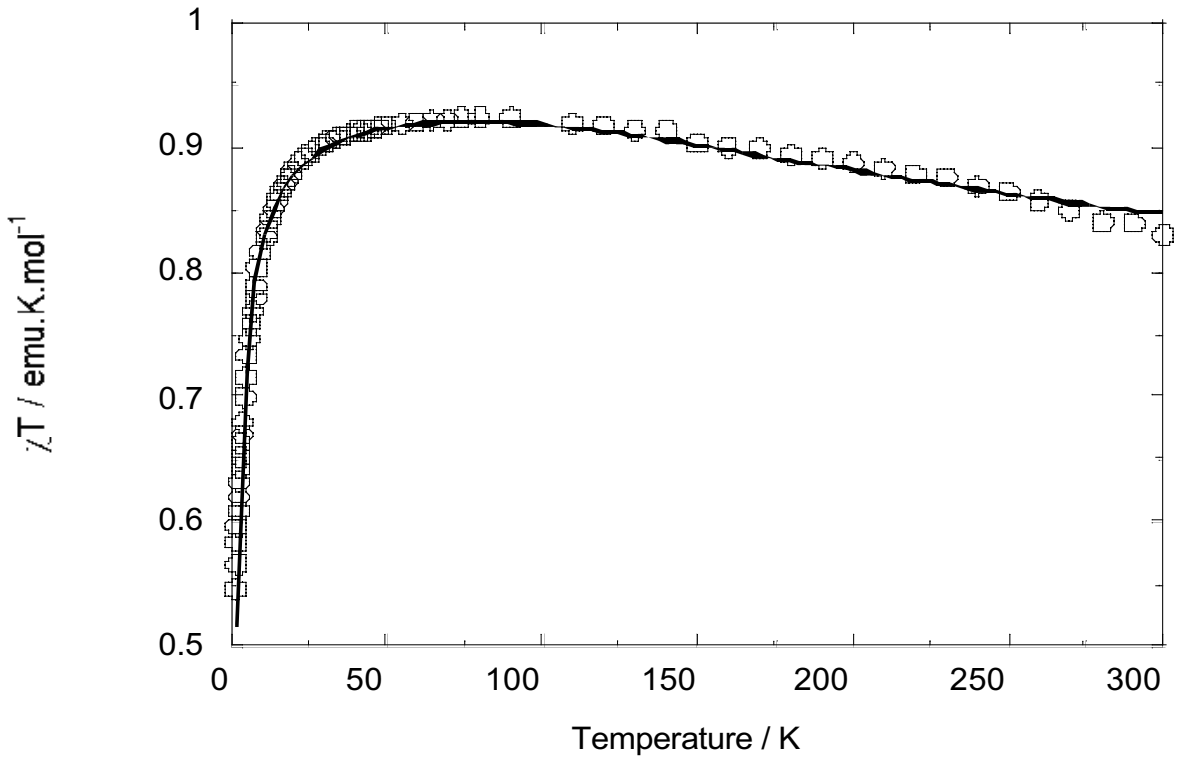

Figure 4 